\title{
Pneumomediastinum in COVID-19: Merely a Matter of Lung Frailty?
}

\author{
Khevan Somasundram $^{\mathrm{a}}$ Kaladerhan Agbontaen ${ }^{\mathrm{a}}$ Suveer Singh ${ }^{\mathrm{a}, \mathrm{b}}$ \\ antensive care unit, Chelsea and Westminster Hospital, London, UK; ${ }^{b}$ Intensive care unit, Royal Brompton Hospital, \\ London, UK
}

\section{Dear Editor,}

Pneumomediastinum describes the presence of free air in the mediastinum. It is an uncommon diagnosis [1]. The natural history is of resolution with conservative management. However, albeit rarely, propagation and accumulation of air within the enclosed mediastinum, can progress to tension pneumomediastinum, with cardiorespiratory compromise [2].

Reports of pneumomediastinum in patients hospitalized due to infection by the beta coronavirus severe acute respiratory syndrome (SARS-CoV-2), (COVID-19) are regenerating awareness of this hitherto infrequent occurrence $[3,4]$. They describe subsets of patients developing spontaneous pneumomediastinum, having had no exposure to positive pressure ventilatory support [5-7]. Moreover, the description of spontaneous pneumomediastinum during the smaller outbreak of severe acute respiratory syndrome coronavirus (SARS-CoV-1) outbreak in 2003 was independently associated with increased intubation rates and risk of mortality $[8,9]$. And so, in the absence of a definitive description concluding the development of pneumomediastinum in COVID-19 due to positive pressure ventilation thus far, natural questions arise regarding the aetiology of pneumomediastinum.

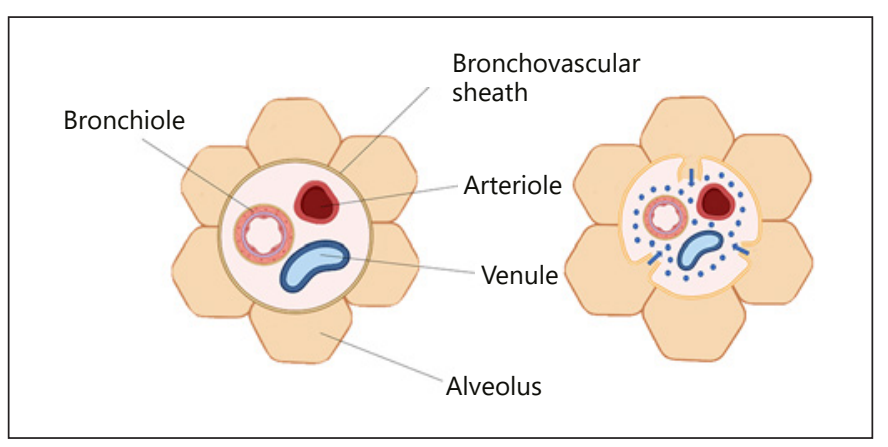

Fig. 1. Alveolar rupture with movement of air into the bronchovascular sheath.

What anatomico-mechanical risk factors predispose to pneumomediastinum? And is there a unifying mechanism of injury directly due to COVID-19 pneumonitis that underlies the pathophysiology of this complication? Further, why do those with predisposing factors and apparently conducive circumstances not necessarily develop pneumomediastinum?

Air in the mediastinum can arise from varied causes at a number of contiguous anatomical regions (Table 1). In the setting of COVID-19 pneumonitis, pneumomediasti-

\section{(C) 2021 The Author(s)}

Published by S. Karger AG, Basel

This is an Open Access article licensed under the Creative Commons Attribution-NonCommercial-4.0 International License (CC BY-NC) (http://www.karger.com/Services/OpenAccessLicense), applicable to the online version of the article only. Usage and distribution for commercial purposes requires written permission.
Correspondence to:

Suveer Singh, suveer.singh@imperial.ac.uk 


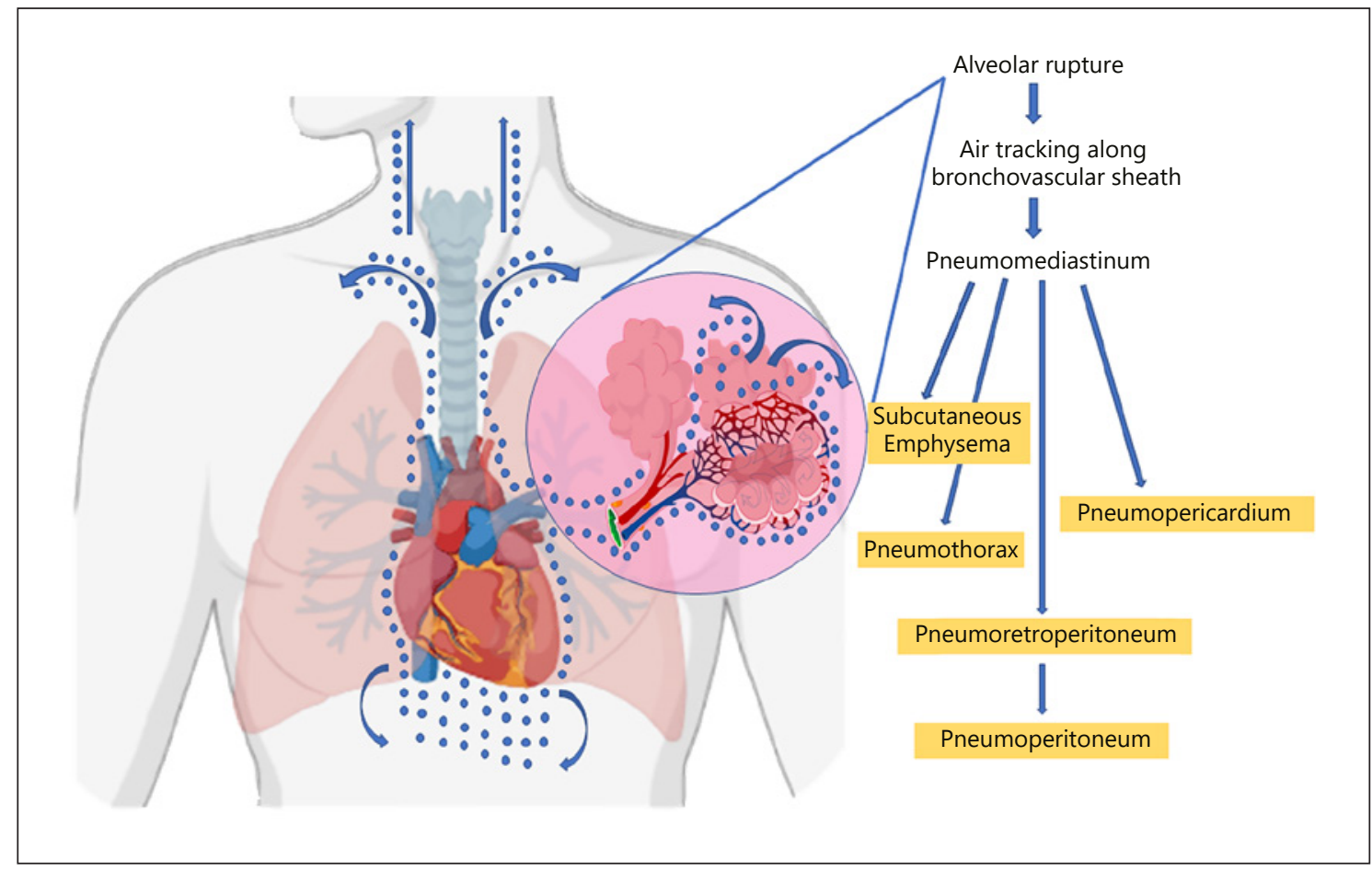

Fig. 2. The visceral mediastinal compartment demonstrates extension of the mediastinal pleural beyond the pulmonary hilum, continuous with the distal bronchovascular sheath. The sequel of the propagation of air in the mediastinum leads to its accumulation in contiguous anatomical locations.

Table 1. Causes of pneumomediastinum by origin

\begin{tabular}{|c|c|c|c|c|c|}
\hline Upper respiratory tract & Intrathoracic airways & Lung parenchyma & $\begin{array}{l}\text { Gastrointestinal } \\
\text { tract }\end{array}$ & Trauma & $\begin{array}{l}\text { Infection with } \\
\text { gas-producing } \\
\text { organisms }\end{array}$ \\
\hline Facial fracture & $\begin{array}{l}\text { Iatrogenic (bronchoscopy, } \\
\text { transbronchial biopsy, needle } \\
\text { aspiration) }\end{array}$ & $\begin{array}{l}\text { Spontaneous alveolar } \\
\text { rupture }\end{array}$ & & & \\
\hline
\end{tabular}

Oropharyngeal mucosal

disruption

num is thought to be precipitated by sub-pleural alveolar rupture [5]. Free air dissects the peribronchovascular sheath and leaks proximally to reach the mediastinum; the so-called Macklin effect [10] (Fig. 1-3). Lung units in COVID-19 may be more susceptible to alveolar rupture due to increased transalveolar pressures beyond the local stress-strain threshold for epithelial-interstitial integrity. The similarly applied concept in material properties describes fatigue as structural degradation with cyclical loading [11]. In otherwise healthy lungs, spontaneous pneumomediastinum derives from a provoking mechanical mechanism that generates a transient massive rise in transpulmonary pressures that breaches the alveolar strain threshold. In the setting of COVID-19, a combination of factors interacts to reach this endpoint. These include clinical features such as cough and increased work of breathing, with its implication of increased stress applied to the respiratory system. Further, the SARS-CoV-2 

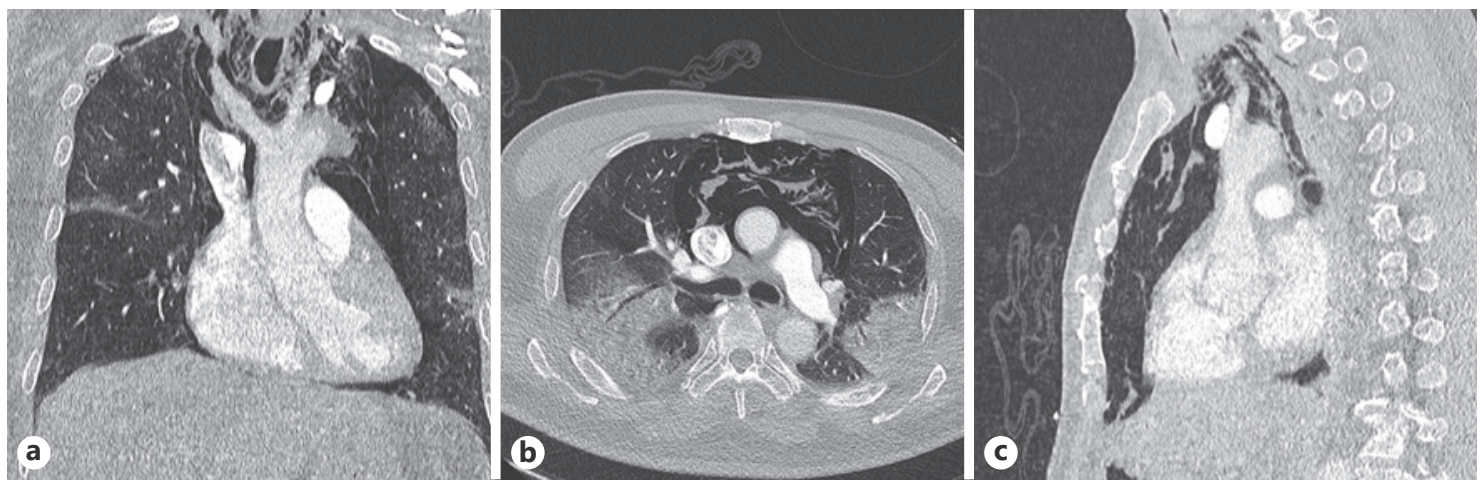

Fig. 3. Pneumomediastinum and left pneumothorax in a non-intubated patient with COVID-19-related pneumonitis (a - coronal, b - axial, and $\mathbf{c}$ - sagittal).

pneumonitis-related epithelial disruption, demonstrated at post-mortem [12], iatrogenic positive pressure respiratory support, and/or indeed patient inflicted self-induced lung injury [13] can all affect structurally frail alveoli that are vulnerable to injury [14].

Cough requires a Valsalva-like effort after the initial inspiratory effort, so as to generate extremely high airway pressures for the subsequent expiratory flow. In the spontaneously breathing patient, the inspiratory phase of the cough requires a rapid forceful activation of the diaphragm and inspiratory musculoskeletal apparatus, to generate a fall in intrathoracic pressure below atmospheric pressure. In doing so, the initial inhalation volume may range between $50 \%$ of the tidal volume, to $50 \%$ of vital capacity [15]. This is followed by a compressive phase, in which the glottis is transiently closed against expiratory effort. Isometric contraction of respiratory muscles (diaphragm, intercostal, and accessory muscles), which limits the rise in transpulmonary airway pressure by increasing pleural pressure, thereby preventing the barotrauma that would ensue through the generation of intrathoracic pressures up to $\sim 400 \mathrm{~cm} \mathrm{H}_{2} \mathrm{O}$ [15]. Cough creates a traumatic mechanical stress upon the airway wall, with neutrophilic airway inflammation and increased cough hypersensitivity that is self-propagating in animal models [16]. Microscopic injury to the respiratory epithelial mucosa by such a self-perpetuating cycle has been demonstrated clinically in chronic obstructive pulmonary diseases and lower respiratory tract infections [17-19].

"Effort-induced lung injury" caused by increased spontaneous respiratory effort results from the generation of large negative intra-pleural pressures $\left(P_{\mathrm{pl}}\right)$ with already elevated airway pressures $\left(P_{\mathrm{aw}}\right)$, directly resulting in an increased transalveolar pressure. This translates into an equivalent transpulmonary pressure $\left(P_{\mathrm{L}}\right)$ at the end of inspiration and expiration.

$$
P_{\mathrm{L}}=P_{\mathrm{aw}}-P_{\mathrm{pl}}
$$

In healthy lungs, transmitted airway pressures rely on interdependence to ensure that forces acting on one segment of the lung are equally distributed along the visceral pleura, with all alveoli subjected to similar transalveolar pressures so dissipating the tensile forces $[20,21]$. In inflamed lungs with de-recruited alveoli and airway oedema, the oscillations of negative pleural pressures created by vigorous diaphragmatic contractions during respiratory distress causes heterogeneous deformation stress in different pulmonary segments. In patients with moderate to severe SARS-CoV-2, lungs are ventilated in an inhomogeneous fashion with variations in parenchymal aeration [20]. A solid-like behaviour develops in response to inflation forces, with poorer equilibration of airway pressures. This leads to a focal concentration of stress at the interface between collapsed and ventilated alveolar segments. At this point of transition, these partially open alveoli experience elevated traction forces to recruit them with supra-physiological transalveolar pressures from adjacent better-expanded lung units. Studies have calculated that at a transpulmonary pressure of $30 \mathrm{~cm} \mathrm{H}_{2} \mathrm{O}$, inflation pressures can reach as high as $140 \mathrm{~cm} \mathrm{H}_{2} \mathrm{O}$ in injured lungs [21, 22].

SARS-CoV-2 results in severe diffuse alveolar damage with autopsy series in patients who died directly due to SARS-CoV-2 infection, consistently identifying distal pulmonary epithelial involvement as diffuse alveolar injury, and in other areas, concurrent exuberant fibrosis $[23,24]$ (Fig. 4). In addition, the proximal airway is an 

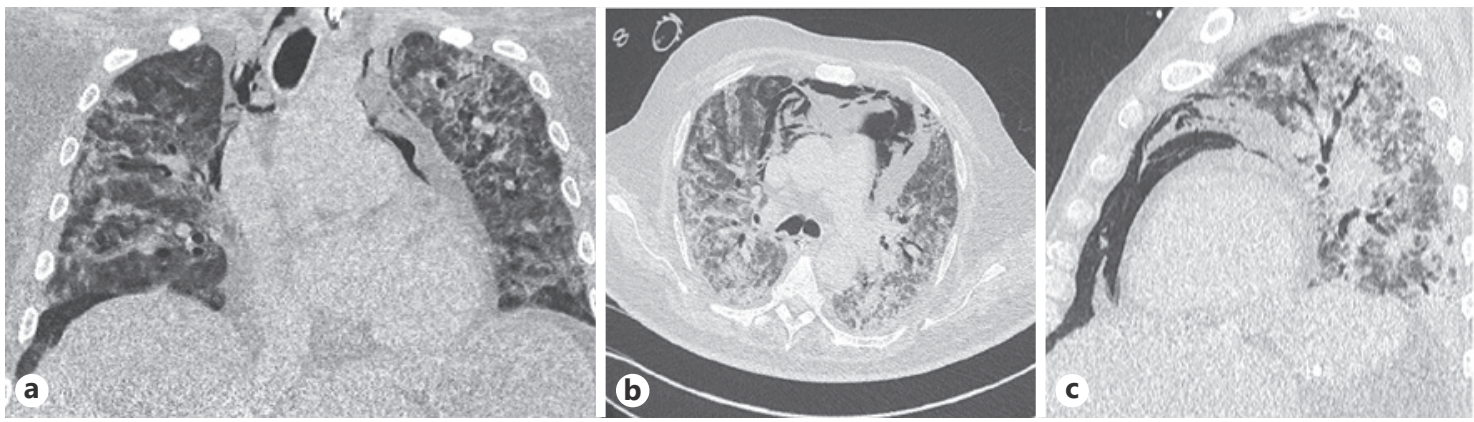

Fig. 4. Pneumomediastinum in an intubated patient with COVID-19-related pneumonitis (a - coronal, b - axial, and c-sagittal).

established site of disease manifestation with notable tracheobronchitis [12, 24-26]. Inflammatory involvement has also been demonstrated by scintigraphy imaging [27]. Importantly, these findings to varying degrees have been re-producible in nonsmokers, and in patients who did not receive mechanical ventilation [12, 24-26].

The inflammatory pulmonary pathology imposed by SARS-CoV-2 infection is now well documented. Moreover, there is notable heterogeneity in intrinsic respiratory mechanics that probably reflects unmeasureable variations in anatomical and physiological lung strain, both in spontaneously breathing and mechanically ventilated patients [28]. Thus, while the aforementioned contributory mechanical, inflammatory, and perpetuating factors to create pneumomediastinum exist, the majority of patients with COVID pneumonitis do not develop it. There would therefore appear to be a missing factor or individual critical threshold for the interaction of these components.

No clear answers related to pressure effects emerge from the available clinical studies, in those with low or higher risk of barotrauma. In case series of those with early COVID-19 and high lung compliance, pneumomedistinum is not widely reported. In a cohort of 169 mechanically ventilated patients with COVID-19 and poorly compliant lungs, Lemmers et al. [5] reported $13 \%$ who developed pneumomediastinum. None had a known history of COPD. Pneumomediastinum was detected mean 3.5 days (SD 0.25-7.5) following intubation. Respiratory system compliance at admission was not significantly different between those who did (not) develop pneumomediastinum (median 28; IQR 22-36 vs. 27; 22-33 $p=0.55$ ) [5]. "Protective" low volume ventilatory strategy was reported [29]. Interestingly, the authors report that airway pressures were lower on the day pneumomediastinum was detected, compared to when mechanical ventilation was initiated. Lemmers et al. [5] suggest therefore that given pneumomediastinum was found to develop when airway pressures were not elevated, it would be more accurate to attribute such findings to the "lung frailty" caused by the underlying disease process of COVID-19 as opposed to barotrauma [5].

Despite the plausibility of the aforementioned mechanisms which may involve a combination of bronchioloalveolar inflammation associated epithelial-interstitial rupture, transalveolar stress, differential strain (with or without purely distributed (self) imposed mechanical thoracic energy for the development of pneumomediastinum), visual demonstration of the Macklin effect has not been shown. Furthermore, the absence of pneumothorax in high-resolution CT scans in certain cases of pneumomediastinum, sustains the further question of whether and how air can reach the mediastinum without causing a visible breach in the alveolar lung parenchyma $[30,31]$.

The re-emergence of clinical interest in pneumomediastinum as a result of its proportion of the sheer number of cases of respiratory failure due to COVID-19 provides an opportunity for further detailed mechanistic study into its origins and whether the "Macklin" effect can be demonstrated. A proposed strategy could be to perform real-time MRI with fluorine-19 to interrogate the ventilated airspaces, which may reveal the route by which contained air leaks out of the tracheobronchial tree with mediastinal extension [32]. An intriguing question as to the cause of spontaneous cause of pneumomediastinum in de novo COVID pneumonitis in previously healthy individuals remains open for now.

\section{Conflict of Interest Statement}

The authors have no conflicts of interest to declare. 


\section{Funding Sources}

This work did not receive any funding.

\section{Author Contribution}

K.S. contributed to project design, literature search, writing, and editing manuscript. K.A. contributed to literature search, original image illustration, writing, and editing manuscript. S.S. contributed to project design and administration, and editing manuscript.

\section{References}

1 Kouritas VK, Papagiannopoulos K, Lazaridis G, Baka S, Mpoukovinas I, Karavasilis V, et al. Pneumomediastinum. J Thorac Dis. 2015 Feb;7(Suppl 1):S44.

2 Campisi A, Poletti V, Ciarrocchi AP, Salvi M, Stella F. Tension pneumomediastinum in patients with COVID-19. Thorax. 2020 Dec 1; 75(12):1130-1.

3 Gasser CR, Pellaton R, Rochat CP. Pediatric spontaneous pneumomediastinum: narrative literature review. Pediatr Emerg Care. 2017 May 1;33(5):370-4.

4 Weissberg D, Weissberg D. Spontaneous mediastinal emphysema. Eur J Cardiothorac Surg. 2004 Nov 1;26(5):885-8.

5 Lemmers DHL, Abu Hilal M, Bnà C, Prezioso C, Cavallo E, Nencini N, et al. Pneumomediastinum and subcutaneous emphysema in COVID-19: barotrauma or lung frailty? ERJ Open Res. 2020 Oct 1;6(4).

6 Mohan V, Tauseen RA. Spontaneous pneumomediastinum in COVID-19. BMJ Case Rep. 2020 May 1;13(5):e236519.

7 Goldman N, Ketheeswaran B, Wilson H. COVID-19-associated pneumomediastinum. Clin Med. 2020 Jul;20(4):e91-2.

8 Peiris JS, Chu CM, Cheng VC, Chan KS, Hung IF, Poon LL, et al. Clinical progression and viral load in a community outbreak of coronavirus-associated SARS pneumonia: a prospective study. Lancet. 2003 May 24; 361(9371):1767-72.

9 Chu CM, Leung YY, Hui JY, Hung IF, Chan VL, Leung WS, et al. Spontaneous pneumomediastinum in patients with severe acute respiratory syndrome. Eur Respir J. 2004 Jun 1; 23(6):802-4.

10 Macklin CC. Transport of air along sheaths of pulmonic blood vessels from alveoli to mediastinum: clinical implications. Archives of Internal Medicine. 1939 Nov 1;64(5):913-26.

11 Schijve J. Fatigue of structures and materials in the 20th century and the state of the art. Int J Fatigue. 2003 Aug 1;25(8):679-702.

12 Borczuk AC, Salvatore SP, Seshan SV, Patel SS, Bussel JB, Mostyka M, et al. COVID-19 pulmonary pathology: a multi-institutional autopsy cohort from Italy and New York City. Mod Pathol. 2020 Nov;33(11):2156-68.
13 Grieco DL, Menga LS, Eleuteri D, Antonelli M. Patient self-inflicted lung injury: implications for acute hypoxemic respiratory failure and ARDS patients on non-invasive support. Minerva Anestesiol. 2019 Sep 1;85(9):101423.

14 Koons B, Greenland J, Diamond J, Singer J. Pathobiology of frailty in lung disease. Transl Res. 2020 Jul;221:1-22.

15 McCool FD. Global physiology and pathophysiology of cough: ACCP evidence-based clinical practice guidelines. Chest. 2006 Jan 1; 129(1):48S-53S.

16 Hara J, Fujimura M, Ueda A, Myou S, Oribe Y, Ohkura N, et al. Effect of pressure stress applied to the airway on cough-reflex sensitivity in Guinea pigs. Am J Respir Crit Care Med. 2008 Mar 15;177(6):585-92.

17 Choudry NB, Fuller RW. Sensitivity of the cough reflex in patients with chronic cough. Eur Respir J. 1992 Mar 1;5(3):296-300.

18 Gasser CR, Pellaton R, Rochat CP. Pediatric spontaneous pneumomediastinum: narrative literature review. Pediatr Emerg Care. 2017 May 1;33(5):370-4.

19 Weissberg D, Weissberg D. Spontaneous mediastinal emphysema. Eur J Cardiothorac Surg. 2004 Nov 1;26(5):885-8.

20 Cruces P, Retamal J, Hurtado DE, Erranz B, Iturrieta $\mathrm{P}$, González $\mathrm{C}$, et al. A physiological approach to understand the role of respiratory effort in the progression of lung injury in SARS-CoV-2 infection. Crit Care. 2020 Dec; 24(1):494-0.

21 Whitehead T, Slutsky A. The pulmonary physician in critical care 7: ventilator induced lung injury. Thorax. 2002 Jul;57(7):635.

22 Mead J, Takishima TA, Leith DA. Stress distribution in lungs: a model of pulmonary elasticity. J Appl Physiol. 1970 May;28(5):596608.

23 Kangas-Dick A, Gazivoda V, Ibrahim M, Sun A, Shaw JP, Brichkov I, et al. Clinical characteristics and outcome of pneumomediastinum in patients with COVID-19 pneumonia. J Laparoendosc Adv Surg Tech A. 2021 Mar; 31(3):273-278.

24 Fox SE, Akmatbekov A, Harbert JL, Li G, Quincy Brown J, Vander Heide RS. Pulmo- nary and cardiac pathology in African American patients with COVID-19: an autopsy series from New Orleans. Lancet Respir Med. $2020 \mathrm{Jul}$ 1;8(7):681-6.

25 Calabrese F, Pezzuto F, Fortarezza F, Hofman P, Kern I, Panizo A, et al. Pulmonary pathology and COVID-19: lessons from autopsy. The experience of European pulmonary pathologists. Virchows Arch. 2020 Jul 9;477: 359-72.

26 Roncati L, Bergonzini G, Lusenti B, Nasillo V, Paolini A, Zanelli G, et al. High density of IgG4-secreting plasma cells in the fibrotic tissue from a surgically resected tracheal ring impaired by complex subglottic stenosis posttracheostomy as immune expression of a Th2 response due to severe COVID-19. Ann Hematol. 2020 Aug 28:1-2. Epub ahead of print

27 Verger A, Bahloul A, Melki S, Karcher G, Imbert L, Marie PY. Tracheobronchitis signs observed on ventilation lung scintigraphy during the course of COVID-19 infection. Eur J Nucl Med Mol Imaging. 2020 Oct;47:270910.

28 Marini JJ, Gattinoni L. Management of COVID-19 respiratory distress. JAMA. 2020 Jun 9;323(22):2329-30

29 Fan E, Del Sorbo L, Goligher EC, Hodgson CL, Munshi L, Walkey AJ, et al. An official American Thoracic Society/European Society of Intensive Care Medicine/Society of Critical Care Medicine clinical practice guideline: mechanical ventilation in adult patients with acute respiratory distress syndrome. Am J Respir Crit Care Med. 2017 May 1;195(9): 1253-63.

30 Hayrabedian M, Sreedhar R, Nayeemuddin F. Pneumomediastinum in a critically ill coronavirus disease 2019 (COVID-19) patient. Chest. 2020 Oct;158(4):A765.

31 Chu CM, Leung YY, Hui JY, Hung IF, Chan VL, Leung WS, et al. Spontaneous pneumomediastinum in patients with severe acute respiratory syndrome. Eur Respir J. 2004 Jun 1; 23(6):802-4.

32 Fox MS, Gaudet JM, Foster PJ. Fluorine-19 MRI contrast agents for cell tracking and lung imaging. Magn Reson Insights. 2015 Jan;8: 53-67. 